Revista de Filosofía

ISSN: 0034-8244

http://dx.doi.org/10.5209/resf.72293

\title{
El constructivismo posmodernista: historia de una doctrina anticientífica
}

\author{
Javier Pamparacuatro Martín ${ }^{1}$
}

Recibido: 11 de marzo de 2019 / Aceptado: 2 de mayo de 2019

Resumen. El presente estudio trata de ser una aproximación histórica al posmodernismo en una de sus vertientes: el constructivismo, la teoría que defiende que el mundo es construcción social sin correlato objetivo alguno. A través del examen de la genealogía de este perfil, el artículo se propone mostrar que el constructivismo es deudor de diversas tradiciones de pensamiento irracionalista, subjetivista e idealista, y que por ello constituye una doctrina anti y pseudocientífica.

Palabras clave: posmodernismo; constructivismo; construcción social.

\section{[en] Post-modern constructivism: history of an antiscientific doctrine}

\begin{abstract}
The present paper is a historical approach to postmodernism in one of its dimensions: constructivism, the theory that holds the world is a social construction with no outward objective correspondence. Through the analysis of the genealogy of this dimension, the article aims to show that constructivism is greatly indebted to diverse lines of irrationalist, subjectivist and idealist thought, and therefore it is necessarily an anti and pseudoscientific doctrine.
\end{abstract}

Keywords: postmodernism; constructivism; social construction.

Sumario: 1. Introducción; 2. Génesis; 3. Subjetivismo-idealismo, fenomenismo, convencionalismo, actitud anticientífica; 4. Sociologismo, historicismo, relativismo, pragmatismo; 5. Negación de la naturaleza humana; 6. Fundación del constructivismo: el externalismo radical de Fleck y su continuación en Kuhn; 7. Glosocentrismo, relativismo epistemológico; 8. La tesis de la falsa conciencia; 9. Conclusión; 10. Referencias bibliográficas.

Cómo citar: Pamparacuatro Martín, J. (2020): "El constructivismo posmodernista: historia de una doctrina anticientífica”, en Revista de Filosofía 45 (2), 375-396.

\footnotetext{
Facultad de Letras

Departamento de Lingüística y Estudios Vascos

Universidad del País Vasco

javier.pamparacuatro@ehu.eus
} 


\section{Introducción}

El posmodernismo, fenómeno intelectual siempre dificil de delimitar, presenta una amplia variedad de aspectos. Uno de ellos es el lingüístico, que cuenta a su vez por lo menos con dos vertientes: el textualismo y el constructivismo ontológico. Las dos son caras de un prisma, la cuestión lingüística, en el que cristaliza buena parte de la filosofía contemporánea. Las dos son corrientes muy en boga en las ciencias sociales y en las humanidades, y sus efectos culturales sin duda subsisten con vigor pleno. Las dos son pseudociencia y pensamiento anticientífico revestidos de novedad. No otra cosa que novedad quiere transmitir la expresión de Rorty con que se conoce el movimiento en que se inscriben: «giro lingüístico» (linguistic turn) ${ }^{2}$.

En contra de lo que el prefijo pos- de «posmodernismo» insinúa, ni el textualismo ni el constructivismo (o construccionismo) ${ }^{3}$ son corrientes nuevas ni suponen giro alguno, sino que son una revisitación y amalgama de corrientes filosóficas antiguas, o al menos ya existentes (las razones de su éxito estriban en todo caso en su novedad percibida, no en su novedad real, y obedecen a motivaciones extrateóricas en las que no entraremos). En esencia, el textualismo considera que los hechos sociales, culturales y, en buena medida, también los naturales, son textos, signos, que el estudioso debe saber leer. El constructivismo (entiéndase en este artículo: el ontológico u «ontoconstructivismo») $)^{4}$ puede ser individual o social. Este último sostiene que lo que llamamos realidad no es otra cosa que construcciones sociales e históricas, sin correlato objetivo independiente de nuestras mentes.

La visión ontoconstructivista ha cosechado un éxito arrollador y ha gozado de una extraordinaria difusión en el mundo académico contemporáneo gracias a Kuhn, Foucault y Feyerabend. Bosquejada por el último Husserl (1931) y desarrollada por Fleck (1935), la adoptaron más tarde algunos sociólogos (por ejemplo, Berger y Luckmann, en La construcción social de la realidad, de 1967) y la nueva sociología de la ciencia (el llamado «Programa Fuerte» de esa disciplina representado por Latour, Barnes, Woolgar, Bloor, Knorr-Cetina, Pinch, Harry M. Collins...). A la visión constructivista se contrapone el objetivismo o realismo, para el cual muchos hechos relativos al mundo se producen sin el concurso de los seres humanos y con total independencia de ellos.

2 Esta expresión figura en el título de una antología de textos-manifiesto dirigida por el mencionado autor (Rorty, 1967).

3 En el ámbito en que nos movemos, pueden usarse ambos términos indistintamente. No obstante, con objeto de evitar equívocos, debemos advertir de que, en otros contextos distintos al presente, se ha reservado el término «constructivismo» o «constructivismo social» para designar a una teoría psicológica y pedagógica basada en los trabajos de Piaget y Vygotski (McKinley, 2015; Taylor, 2018). En tales contextos (por ejemplo, Taylor, 2018, pp. 217-218), el constructivismo se distinguiría del «construccionismo», y de su variante principal, el «construccionismo social» o «socioconstruccionismo», que aquí abordamos, con los que no tiene ninguna relación.

4 Propiamente, el constructivismo, sin adjetivos, postula que nada está dado y que todo es construido. Para el constructivismo epistemológico (distinto del ontológico que aquí estudiamos), desde Aristóteles, Kant, Engels, Einstein, Piaget y Popper, todos los conceptos y teorías son construcciones humanas. El constructivismo epistemológico «[s]e opone al empirismo, que afirma que todas las ideas son perceptos o se derivan directamente de ellos» (Bunge 1999, p. 410).

5 «En última instancia es únicamente el descubrimiento de los horizontes de la experiencia el que aclara la realidad efectiva del mundo y su trascendencia, y luego lo muestra como inseparable de la subjetividad trascendental que constituye el sentido y la realidad del ser» (Husserl 1997, p. 83). 
Obviamente, hay muchas cosas que son construcciones sociales: las instituciones, los signos y símbolos, los conceptos que se manejan en las ciencias sociales, etc. Pero el constructivismo va mucho más allá de la afirmación banal de que gran parte de lo social es construido de una $\mathrm{u}$ otra forma, $\mathrm{y}$ asegura, con respecto a cualquier hecho, del ámbito que sea (incluso natural), que los seres humanos lo hemos construido. Según esta corriente, ningún hecho existe independientemente de las sociedades y sus necesidades e intereses. En particular, el constructivismo proclama que todas las supuestas verdades o certidumbres científicas son convenciones inventadas por la ciencia, no siendo la realidad independiente del sujeto cognoscente, sino su producto. Así, Latour y Woolgar afirman: «"la exterioridad” [es decir, el "estar-ahí”, el mundo exterior] es consecuencia del trabajo científico, no su causa $\rangle^{6}$. Como meras construcciones sociales, los descubrimientos, teorías y conceptos científicos son por tanto contingentes y relativos. Al propugnar que no existe realidad objetiva que la ciencia pueda aspirar a explicar, predecir y controlar, el constructivismo se alza como plataforma que sirve al propósito de atacar al conocimiento científico. Con su pretensión de que solo hay discursos socialmente construidos, el constructivismo, al igual que el textualismo, desincentiva la exploración del mundo, la búsqueda de la verdad objetiva, y desalienta la crítica, la reflexión y el estudio.

Este artículo aborda el estudio histórico del constructivismo ontológico acentuando el hecho de que deriva de corrientes irracionalistas, subjetivistas e idealistas. El constructivismo es estudiado aquí en tanto que representa una forma de pensamiento anti y pseudocientífico que es coherente con su pasado intelectual. No se abordarán las variadas formas de anticiencia y pseudociencia que reviste en la actualidad el constructivismo, ya que de ellas se han ocupado otros trabajos ${ }^{7}$. El marco teórico en el que se encuadra la crítica que se lleva a cabo en estas páginas es el realismo científico, uno de cuyos representantes y defensores más destacados es Mario Bunge ${ }^{8}$. El realismo científico, distinto al realismo ingenuo o espontáneo, defiende que es posible aprehender, aunque solo sea parcial y gradualmente, ciertos aspectos objetivos de la realidad siguiendo la estrategia general de adquisición de conocimiento denominada enfoque científico ${ }^{9}$. Para el realismo científico, la ciencia es la más importante y exitosa (si bien falible) fuente de conocimiento acerca del mundo ${ }^{10}$.

\footnotetext{
Latour y Woolgar (1995), p. 204.

Resaltamos de manera particular el libro de Sokal y Bricmont (1998). Al contrario que la ciencia, el constructivismo no aprende de los errores. Miller, recientemente, al reparar en que «el lenguaje por sí mismo no basta para dar cuenta de la realidad material desde un punto de vista ontológico», recurre a la física cuántica con el fin de dotar al constructivismo de una «ontología realista» (Miller 2016, p. 377). El entrelazamiento cuántico, la función de onda, la interacción de los aparatos de medida, etc., son principios y conceptos de la física cuántica que Miller (siguiendo a autores como Alexander Wendt) emplea de manera pretenciosa, incompetente y absurda en un empeño de sustentar su «realismo contextual», sin, al parecer, sospechar que el abuso posmodernista de la ciencia ya había sido desacreditado de modo eficaz por Sokal y Bricmont.

$8 C f$., especialmente, Bunge (2006), aunque la defensa y justificación del realismo y la crítica a las distintas variedades de antirrealismo se hallan a lo largo de gran parte de la vasta obra de este autor. El realismo científico, como filosofía inherente a la ciencia, presenta distintas dimensiones (semántica, ontológica, epistemológicometodológica, ética) que Bunge desarrolla en una obra monumental (Treatise on basic philosophy, 1974-1989, 8 vols.).

9 El concepto de enfoque científico es más amplio que el de método científico y lo engloba. Alude a las bases y requisitos genéricos que asume la ciencia (Bunge 1983, pp. 194-239).

10 Mallon (2019).
} 
El realismo espontáneo se ha mostrado insuficiente para refutar de manera decisiva el constructivismo. A pesar de que ha surgido algún intento por revivir la controversia entre realismo y antirrealismo ${ }^{11}$, lo cierto es que esta se agotó hace décadas sin haber llegado a ninguna conclusión iluminadora ${ }^{12}$. Solo pueden darse garantías de éxito en la labor de impugnación del constructivismo si interviene una filosofía de la ciencia que, entre otros cometidos, se ocupe de enlazar el abigarrado dominio de las construcciones humanas -sobre todo de las menos obvias, aunque no solo de ellas- con su referente mundano; en otras palabras, solo es posible con la mediación del realismo científico. Sobre todo, el realismo científico incide en un elemento fundamental: la ciencia no prueba la existencia de la realidad; la da por supuesta, proporcionando indicios suficientes de que más allá de nuestra mente hay algo más que nuestros constructos. En cuanto al realismo crítico, si bien como corriente general en la cual se inscribe el realismo científico se opone, igual que este, al realismo ingenuo y a posiciones antirrealistas, como teoría o sistema filosófico ${ }^{13}$ no permite ejercer la crítica al constructivismo y a su irracionalismo, subjetivismo e idealismo históricos en todos los diversos frentes que presentan.

El posmodernismo se ha configurado sobre terreno de aluvión. Se ha formado en un ámbito en el que han confluido de manera intrincada y sin orden múltiples y aparentemente heterogéneas influencias filosóficas. Esta es una de las claves para entenderlo, y, como enseguida veremos, es particularmente relevante para entender el constructivismo. En conexión con esta observación, una segunda que es pertinente realizar atañe a las dificultades inherentes a un intento de hacer una historia de las ideas que rompa con el modo tradicional de estudio de la disciplina. Mientras el tradicional es un enfoque predominantemente sincrónico, que concibe el devenir del pensamiento humano (sobre todo, el filosófico) como una sucesión de estados compartimentados en capítulos que se enlazan entre sí por vínculos tópicamente asumidos, la nueva orientación, en cambio, trata de captar en su fluir auténtico, no solo los sistemas de pensamiento, sino también las ideas en su sentido más lato.

El constructivismo aparece como un artefacto manufacturado en el siglo XX a partir de diversas materias primas filosóficas. Por mejor decir, procede de un «achatarramiento» y compactación de distintas corrientes que hace difícil discernir el peso relativo de cada una de ellas. El recorrido que aquí presentamos por los antecedentes filosóficos del constructivismo no pretende ser exhaustivo, ni en la nómina de autores y corrientes, ni mucho menos en la explicación de su aportación. La cuestión de los antecedentes se asemeja por su complicación a una madeja con varios cabos, cada uno de los cuales es una dimensión evolutiva del fenómeno del constructivismo, privativamente suya o no. Estas dimensiones son: el glosocentrismo, el subjetivismo, el idealismo, el irracionalismo, la actitud anticientífica y el rechazo a la idea de verdad como correspondencia del juicio con la realidad, la negación de la naturaleza humana, la disolución del individuo en las relaciones sociales (o sociologismo), el relativismo, el pragmatismo y, finalmente, la idea de falsa conciencia. En su devenir, las dimensiones evolutivas -sus respectivas corrientes o autores- son concomitantes, o se influyen y refuerzan, o se entrelazan o

\footnotetext{
Uno de esos intentos es el que emprende Kukla (2000).

Rouse (2002), p. 62.

Uno de los representantes actuales más notables del realismo crítico como sistema filosófico es Roy Bhaskar. A partir de su obra se ha originado un movimiento intelectual consolidado (Taylor 2018, p. 217).
} 
confunden, mostrando grados variables de autonomía. Esas relaciones aquí quedan más sugeridas que señaladas y explicadas. En la presente investigación -conviene asimismo precisar-, solo tendremos en cuenta las influencias directas, y así, no se considerará, por ejemplo, a Bergson, ya que nunca influyó en las ciencias sociales, salvo de manera indirecta por su antiintelectualismo. Por la misma razón, tampoco han sido abordadas, pongamos por caso, determinadas versiones de irracionalismo o escepticismo radical.

Algunas de las dimensiones arriba enumeradas se agrupan en un apartado; otras (irracionalismo, rechazo de la idea de verdad) están presentes a lo largo del trabajo. En la exposición se ha tratado de imprimir en lo posible un orden temporal y lógico a una devenir complejo. Por razones de espacio, y debido al elevado número de autores que pueden considerarse antecedentes del constructivismo, no ha sido posible respaldar en la mayoría de los casos el análisis histórico con citas directas de dichos autores.

\section{Génesis}

Una de las primeras referencias la localizamos en el siglo XIV con Guillermo de Ockham. Aunque en relación al tema que nos ocupa, su proyección es vasta y profunda en varios aspectos, nos centraremos en dos de los puntos en que constituye un antecedente significativo. De alguna manera, estos fueron anticipados por Escoto, pero la actitud que adoptó Ockham de crítica demoledora de los sistemas filosóficos precedentes es radicalmente distinta.

Por una parte, Ockham continúa la tradición nominalista de Abelardo, defendiendo que no hay Ideas ejemplares en Dios, ni esencias o naturalezas universales en el mundo que sean comunes a múltiples individuos, ya que todo lo que existe es singular, y lo universal existe solo como acto mental (intentio) en el alma. El nominalismo de Ockham supuso la ruptura definitiva con la tradición filosófica griega (en el sentido en que se prioriza al individuo y la esencia universal desaparece), y tendrá su continuación en el empirismo. Por otra parte, Ockham incidió mucho más que la tradición que le precedía en la libertad del hombre. Este la experimenta en sí mismo de forma clara e inconcusa: siente que, aunque la razón le dicte algo, la voluntad puede quererlo o no. «Al final de esta línea de pensamiento se hallará la noción moderna de autonomía de la conciencia. La moralidad consiste entonces, para Guillermo de Ockham, en el encuentro de la libertad y de la ley. Sin ley, no hay moralidad, pero sin libertad tampoco hay moralidad $»^{14}$. Sin embargo, la concepción de ley de la filosofía de Ockham significó un vuelco con respecto al pensamiento escolástico. Para Santo Tomás, la ley eterna y natural, aunque procede de Dios, no le es impuesta al hombre, sino que es interiorizada por y en la naturaleza humana. En Ockham, en cambio, la ley que decreta el bien y el mal tiene su origen en la voluntad divina omnipotente, y es una realidad no absoluta, sino contingente, ya que Dios podría haber creado un orden moral distinto u opuesto. Un acto no es bueno o malo en sí mismo; es malo porque Dios lo prohíbe, y bueno porque lo prescribe. De lo cual se desprende que la ley es una imposición al hombre desde el exterior. Esta noción voluntarista de la ley ejerció una amplia repercusión posterior en formas y doctrinas proclives al

14 Delumeau (1992), pp. 112-113. 
relativismo ${ }^{15}$. Por su parte, la concepción ockhamista de libertad y moralidad dejó expedita la vía a teorías que, acentuando la libertad, acabarían negando la existencia de una naturaleza humana. Más adelante, retomaremos esta última idea en relación con la filosofía moral de Kant.

La crítica de Ockham a la filosofía escolástica, en estos asuntos y en otros, tuvo consecuencias e implicaciones que no se han extraído ni ponderado suficientemente. La novedad que supuso su ruptura con la filosofía griega y escolástica -la llamada via moderna- creó las bases de una nueva manera de hacer filosofía. No es solo que su aportación a la ciencia, como se recalca a menudo, sea muy notable. Es también, y sobre todo, que el formidable vacuum que instaura Ockham en Dios, el hombre y la realidad sensible, es el foco del que irradian directa o indirectamente todas las dimensiones evolutivas a que nos hemos referido arriba.

En general, el empirismo, del que Ockham fue precursor, al sostener que todas las ideas son sensaciones e impresiones sensibles o derivados directos suyos, se ve abocado a alguna forma de subjetivismo o idealismo. En la primera mitad del siglo XVIII, Berkeley formulaba que la realidad no existe por sí misma, que «ser es ser percibido». Siguiendo el camino que trazó Ockham en su crítica a la metafísica tradicional, Hume cuestionó nuestro supuesto de que existe un conjunto de principios epistémicos que nos permite alcanzar alguna certeza sobre la realidad. Kant, despertado de su «sueño dogmático» por Hume, coincidió con este en la idea de que no es posible lograr la certidumbre en nuestro conocimiento. Para Kant, no podía haber verdad objetiva porque es imposible el conocimiento de las cosas en sí mismas. «Para él, lo que llamamos "conocimiento" siempre es una construcción, nunca una representación $\rangle^{16}$. Aunque Hume y Kant admitieron que desde un punto de vista práctico podemos estar seguros de muchas cosas, el escepticismo empírico (o empirismo fenomenista) del primero y la idea del segundo de que solo podemos acceder a una realidad aparente prepararon el camino para el advenimiento de un subjetivismo plenamente asumido. Así, F. A. Lange, seguidor de Kant y promotor del neokantismo, resaltó el carácter ilusorio del conocimiento y la relatividad de la distinción entre la verdad y la falsedad ${ }^{17}$.

En este punto, es precisa una aclaración. De las afirmaciones en torno al papel de precursor de Ockham no se sigue que sea lícito atribuirle responsabilidad por los derroteros que siguieron sus sucesores (Hume, por ejemplo). Su insistencia en que las cosas individuales son los únicos existentes no significa que rechace el conocimiento de proposiciones universales en que se basa la ciencia; tampoco realizó ningún intento de reducir las cosas a datos sensibles, o a construcciones lógicas a partir de los datos sensibles: «[é]l habría visto indudablemente semejante reducción como una simplificación excesiva» ${ }^{18}$. Hume y Kant, entre otros, no se mostraron tan razonables. Una gran diferencia con respecto a Ockham es que no entendieron la ciencia, a pesar de los logros que esta había conseguido ya para la época. Ockham la intuyó, por eso no cayó en los errores de sus sucesores, y ello pese a que aún no había surgido la ciencia moderna. Una muestra de la incomprensión que ostentan Hume y Kant ante la ciencia la hallamos en que, aunque confiaban en

15 Delumeau (1992, pp. 113, 117), menciona a Suárez (siglos XVI-XVII), a Medina (siglo XVI) y a los «numerosos moralistas de finales del siglo XVI y de principios del siglo XVII» que los siguieron.

16 Bunge (1999), p. 460.

17 Ibid.

18 Copleston (1979), pp. 67, 80. 
los datos empíricos, no lo hacían en las leyes científicas, a las que consideraban solo síntesis inductivas, generalizaciones empíricas. Pero esta no es la concepción que los científicos tienen de las leyes de la ciencia: estas son generalizaciones pertenecientes a teorías (sistemas hipotético-deductivos), lo que significa que, además de por datos empíricos pertinentes, están apoyadas por otras muchas hipótesis bien corroboradas del sistema ${ }^{19}$. La ruta que tomó la filosofía a partir de Ockham en buena medida se debe a, y se explica por, la ignorancia de en qué consiste realmente el conocimiento científico. Ockham fue el último pensador que pudo ser crítico radical sin caer en el escepticismo.

La crisis y crítica de la filosofía escolástica que supuso Ockham depuró la fe de elementos filosóficos, de helenismo, afirmando la preeminencia de la fe sobre la razón y su autonomía. El ockhamismo no fue de ningún modo, por tanto, un ataque ni siquiera indirecto al dogma cristiano. Sin embargo, transmitió un legado y un procedimiento de reflexión que fueron la base para la formación de una serie de procesos tendentes a la desvalorización del mundo inteligible. Intercambiando los términos, pero siguiendo exactamente la misma lógica que animó a Ockham, el programa de la modernidad, desde el Renacimiento a las Luces, libró a la razón de la fe y de los dogmas de la Iglesia. Por el camino que se abrió a partir de la crisis de la escolástica en el siglo XIV, avanzó paulatinamente un proceso de disolución de lo trascendente y de secularización y descristianización de Occidente.

El romanticismo fue una profundización en esta tendencia histórica. «Tras la apariencia de un simple retroceso, la contrarrevolución abole todos los valores trascendentes, tanto divinos como humanos» ${ }^{20}$. Pero, además, el romanticismo fue una profundización «creativa». La auténtica innovación que el romanticismo representó fue posible por el vacuum que Ockham excavó en la concepción tradicional del hombre, Dios y la realidad, y que logró continuidad en el proyecto emancipatorio de la modernidad. Si Ockham lleva a cabo esta destrucción para preservar a la trascendencia de la especulación (emprendiendo, en su imagen invertida, la modernidad la misión opuesta: proteger a la razón de la trascendencia), los románticos prosiguen la labor crítica de zapa en esa vía ya abierta, pero en su caso para preservar a la inmanencia de la razón: «fulminan todos los dualismos: la eternidad deja de ser enfrentada al tiempo, la esencia a la existencia, lo posible a lo real, lo inteligible a lo sensible e incluso el otro mundo al mundo de acá [...]. El culto que celebran es el de lo fáctico» ${ }^{21}$. Sin embargo, esa destrucción el romanticismo la transforma creativamente; hace de la destrucción, creación.

Desde entonces y hasta el posmodernismo, la historia del pensamiento ha representado en medida muy significativa una revuelta contra el racionalismo y la razón ilustrada y sus aspiraciones al universalismo. El romanticismo inauguró un proceso de reversión total de los valores de la Ilustración, y fue en este crucial sentido una contrarrevolución, un atavismo. «Su odio a la modernidad engendra una concepción del mundo radicalmente nueva. Su nostalgia inaugura en el saber una mutación de la que todavía somos ampliamente tributarios. Esos reaccionarios empedernidos son, a pesar suyo, inventores $\rangle^{22}$. Sin duda, el romanticismo le marcó la pauta al pensamiento

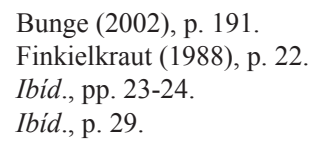


posterior, fijando sus lineamientos básicos. El culto romántico a la subjetividad, a la irracionalidad y al sentimiento, a la acción y voluntad, al individualismo, lo único, a los particularismos, la aversión a la ciencia y a las abstracciones..., son temas demasiado conocidos para insistir en ellos aquí. El romanticismo, un movimiento que, como en tantos aspectos, significó un cambio profundo en la historia de las ideas, catalizó la generación de una serie de transformaciones fundamentales. Sin tener en cuenta los tópoi románticos no se puede explicar la deriva posterior del pensamiento occidental y su culminación en el posmodernismo. El romanticismo es el movimiento que impulsa la generación de las nuevas dimensiones de que hablamos en el primer apartado ${ }^{23}$.

\section{Subjetivismo-idealismo, fenomenismo, convencionalismo, actitud anticientífica}

El recorrido por los antecedentes filosóficos del constructivismo puede continuar con el idealismo alemán, que fue una influencia básica en Fleck, el fundador del constructivismo. Ya en pleno siglo XIX, prosigue con Schopenhauer, para quien «El mundo es mi idea»; con Dilthey, idealista histórico, que sostenía que lo que movía a la sociedad era la mente o espíritu individual (Geist), más que cualquier otra causa material (razón por la cual denominó ciencias del espíritu, Geisteswissenschaften, a las ciencias sociales, contraponiéndolas a las ciencias naturales). En la formación del constructivismo también intervino el intuicionismo -tanto el moderado de Dilthey como el más radical de Husserl-, por cuanto «abre las puertas a la fantasía desmedida e induce a la credulidad ${ }^{24}$.

El recorrido que estamos efectuando continúa, por otra vía, con Mill, que definió la materia como «una posibilidad permanente de sensación»; y con algunas derivaciones del positivismo, que, siguiendo la senda del empirismo tradicional, renuncian expresamente a las nociones de causa y explicación y tildan de metafísicas teorías científicas plausibles pero resistentes a la observación. Así, uno de los fundadores del empiriocriticismo, Mach, heredero del positivismo y empirista radical muy influido por Hume, aseveró que lo que llamamos el mundo o las cosas y el yo son organizaciones cognoscitivas de conjuntos de sensaciones ${ }^{25}$. En el siglo XX, Carnap analizó y sistematizó en La construcción lógica del mundo (1928) esta tesis de Mach (autor que, por otra parte, fue uno de los que más ascendiente tuvieron sobre el positivismo lógico). El título de esta obra recuerda que el positivismo lógico, corriente que el constructivismo rechaza y considera

23 Valgan dos ejemplos. La negación de cualquier esencia humana cuenta con una manifestación explícita en de Maistre: «Cualquier pregunta sobre la naturaleza del hombre debe ser resuelta por la historia» (J. de Maistre, «Des origines de la souveraineté», en Euvres complètes, I, Vitte, Lyon, 1884, p. 316. Citado en Finkielkraut (1988), p. 30. El segundo ejemplo lo proporciona la defensa romántica de «lo único, lo individual, lo concreto, aquello en que una cosa difiere de otras cosas; pues eso es su esencia y su caso, y no aquello que tenga de común con otras cosas» (Berlin 1983, p. 239). La invocación de que el auténtico conocimiento es de lo particular y el rechazo al concepto, la abstracción y la generalidad (de lo cual deriva el desdén hacia la ciencia), también son actitudes románticas. Berlin acredita la influencia de un heredero de Ockham, Hume, sobre uno de los iniciadores del romanticismo, Hamann.

$24 \quad$ Bunge (1999), p. 424.

25 Lenin, defensor del materialismo, criticó severamente el empiriocriticismo (Materialismo y empiriocriticismo, 1909). Veía en él contenidos idénticos al idealismo de Berkeley. Lenin afirmó que esta posición conducía a posiciones solipsistas y a la renuncia al concepto de verdad como correspondencia de los juicios con el mundo físico independiente de ellos. 
hostil, estuvo, sin embargo, «profundamente comprometido con la metáfora de la construcción $»^{26}$. El neopositivismo, semisubjetivista, no es realismo ni materialismo (filosofías auténticamente científicas, a las que acusó de absurdos metafísicos), ya que se quedó anclado en los datos sensoriales y en una metafísica fenomenista, sobreestimando la inducción y recelando de las teorías y las hipótesis ${ }^{27}$. Al final, esta visión limitada sobre la ciencia explica el compromiso profundo del neopositivismo con la idea/metáfora de construcción. Yendo en contra de las premisas originales del neopositivismo, Carnap y Neurath sostuvieron que los enunciados elementales no se justifican por su correspondencia con el mundo exterior, sino por la coherencia y la ausencia de contradicción en una estructura.

Surgido en el mismo seno de la práctica científica y próximo a la escuela empiriocriticista, el convencionalismo - punto de vista más que escuela- critica la ambición de la ciencia de alcanzar valores objetivos y destruye el concepto de hecho considerado como la confirmación eventual de la ley científica ${ }^{28}$. A finales del siglo XIX y principios del XX, los convencionalistas (Poincaré, Duhem, Le Roy, Dingler, Ajdukiewicz) postulan que las aserciones de las ciencias naturales son, en realidad, productos artificialmente instituidos. Aunque la génesis efectiva de la ciencia es empírica, los datos de la experiencia dejan siempre espacio suficiente a la formulación de diversas hipótesis explicativas, todas igualmente válidas desde el punto de vista lógico; la aceptación de una y el descarte de otras no depende de criterios empíricos, sino de razones como la comodidad, o de motivos estéticos. Volveremos a considerar (apartado 8) esta interpretación convencionalista: «una continuación de la filosofía positivista, pero también, en cierto modo, su fracaso, un tipo de reflexión autodestructiva en el marco del estilo positivista de pensamiento ${ }^{29}$.

El posmodernismo heredó la actitud anticientífica de Husserl y Heidegger. Es pertinente señalar la crítica de Heidegger a la concepción, vigente en la civilización occidental desde Platón, de la verdad como certeza, como adecuación del intelecto a la cosa, y del pensamiento y lenguaje en términos representacionales o figurativos. Desde perspectivas distintas, pero dirigidas al mismo objetivo crítico, transitan otras teorizaciones que sustentan al constructivismo. Rorty destaca que «el ataque de Quine-Sellars a la idea kantiana de dos clases de representaciones -intuiciones "dadas" a una facultad, y conceptos (o significados) "dados" a otra- [...] [representa] el intento de abandonar la noción de "una explicación del conocimiento humano" $>$ ". La crítica de Sellars al «mito de lo dado» y el enfoque de Quine de la distinción necesario-contingente ${ }^{31}$ constituyen «dos formas radicales de criticar los fundamentos kantianos de la filosofía analítica» y asimismo de criticar la idea del conocimiento como representación precisa y especular de la naturaleza, ya que esta «requiere una teoría de las representaciones privilegiadas, que sean automática e intrínsecamente precisas $»^{32}$.

\footnotetext{
Hacking (2001), p. 80.

Bunge (1999), pp. 437-438.

Kolakowski (1988), pp. 130, 164.

Ibid., p. 181.

Rorty (1983), p. 170.

31 Básicamente, Sellars es antifundacionalista. La epistemología tradicional, fundacionalista, presume que «el conocimiento está estructurado jerárquicamente. Supone que hay estados cognoscitivos en contacto directo con la realidad que sirven de firme fundamento sobre el cual se construye por diversos métodos inferenciales el resto de nuestro conocimiento» (DeVries 2016). Por su parte, Quine cuestiona la distinción analítico/sintético, rechazando el uso que hizo de la misma el empirismo lógico.

32 Rorty (1983), p. 161.
} 
Derivada de Husserl, Dilthey y Weber, la sociología fenomenológica (Schütz ${ }^{33}$, Berger y Luckmann) es un constructivismo individualista, y su principal contribución a la corriente principal del constructivismo es su posición subjetivista. Para la sociología fenomenológica, todos los hechos sociales son «significativos» (dotados de propósito) y por tanto sujetos a «interpretación» (atribución de propósito). El sociólogo fenomenológico se propone realizar un análisis «de la realidad de la vida cotidiana». Esta «se presenta como una realidad interpretada por los hombres y que para ellos tiene el significado subjetivo de un mundo coherente» ${ }^{34}$. El fenomenólogo afirma que capta directamente los objetos de su estudio, las «estructuras de significados subjetivos» que los individuos interpretan en sí mismos y en otros: «La realidad de la vida cotidiana [...] [n]o requiere verificaciones adicionales sobre su sola presencia y más allá de ella. Esta ahí, sencillamente, como facticidad evidente de por sí e imperiosa. Sé que es real $»^{35}$. Además, obtiene intuición inmediata merced a la «visión de las esencias». En la sociología fenomenológica, todo lo social es espiritual y subjetivo o, todo lo más, intersubjetivo, y no material e independiente del observador $^{36}$. La realidad social es construcción que hay que explorar, no problemas que requieran explicación. No hay lugar, pues, en esta rama de la sociología para el estudio científico de hechos sociales brutos.

La actitud anticientífica de la escuela constructivista por antonomasia, el «Programa Fuerte» de la Sociología del Conocimiento Científico (Strong Programme), se define por el constructivismo social (a diferencia del individualista de la sociología fenomenológica) y el externalismo radical (víd. apartado 6), y por su pragmatismo y relativismo. El «Programa Fuerte» y sus escuelas asociadas ${ }^{37}$ desplazaron a principios de los años setenta a la sociología de la ciencia tradicional (mertoniana), no anticientífica, que había estado vigente desde principios de los años treinta y durante cerca de cuatro décadas. Las nuevas sociologías no solo aspiraban a desbancar a la sociología mertoniana, con cuyos planteamientos normativos eran divergentes, "sino también a la filosofía clásica de la ciencia»" ${ }^{38}$. Ansiaban erigirse en las únicas disciplinas capaces de generar el nuevo enfoque que explicara el conocimiento científico. Mal llamadas "de la ciencia»" ${ }^{39}$, estas sociologías, «más que transformarse en herramientas del análisis sociológico de la ciencia, son enriquecedoras de las seudociencias y verdaderas artífices en la construcción y engrandecimiento de disciplinas anticientíficas ${ }^{40}$.

\section{Sociologismo, historicismo, relativismo, pragmatismo}

Al positivismo de Comte le avalan otras credenciales más como antecedente del posmodernismo. Su actitud fue sociologismo ${ }^{41}$, y allanó el camino a la tesis de

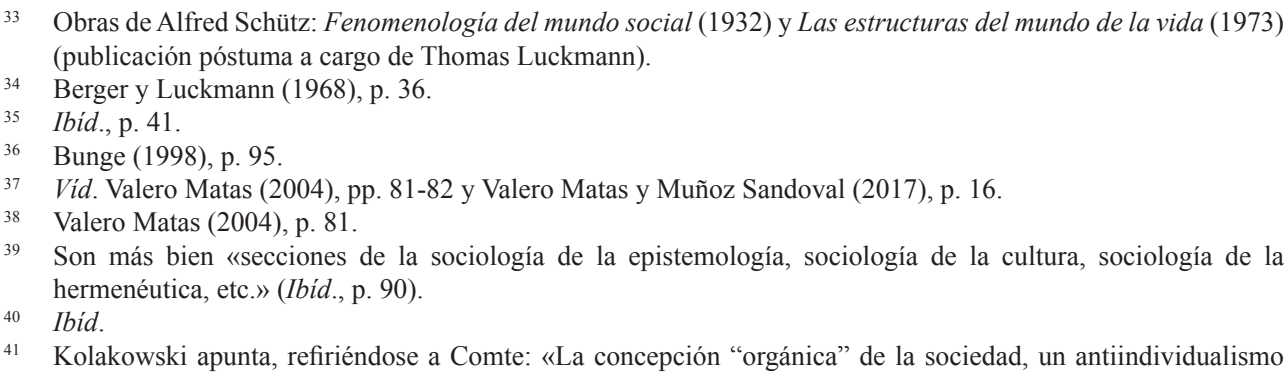


que no hay una razón universal, sino tantas como sociedades existen. En este sentido, otro antecedente que, a caballo entre los siglos XIX y XX, conformaría el relativismo posmodernista fue el historicismo. El historicismo de Spengler y Dilthey hizo depender la comprensión de la realidad de variaciones culturales y de cambio histórico. Así fue como a principios del siglo XX surgió, heredada de Vico y Herder, la teoría de las concepciones del mundo, según la cual las civilizaciones no pueden enjuiciarse con arreglo a un criterio universal. Esta visión la recogió y desarrolló con singular relieve decenios más tarde el filósofo de la ciencia T. S. Kuhn, cuya idea de los paradigmas incomensurables tanto influiría en los teóricos posmodernistas. De Dilthey, los constructivistas Berger y Luckmann destacan su papel de «precursor inmediato» por su «sentido abrumador de la relatividad de todas las perspectivas sobre el acontecer humano, vale decir, de la historicidad inevitable del pensamiento humano» ${ }^{42}$. La insistencia historicista ${ }^{43}$ en que ninguna situación histórica puede entenderse si no es en sus propios términos -continúan explicando los autores- es susceptible de traducirse en un acento en la «condición» social del pensamiento.

La disposición relativista y sociologista está muy relacionada con el pragmatismo, que estima que el individuo es en gran medida el mero reflejo del sentir social, y con Nietzsche. Nietzsche, influido por Spencer, le imprimió una orientación biológica a la perspectiva de F. A. Lange: verdadero es todo lo que promueva la vida; falso es aquello que la pone en riesgo. El pragmatismo de James y Dewey incluyó esta opinión. Estableció que las ideas se miden, no por su adecuación a la cosa conocida, es decir, por su veracidad, sino por el grado en que obtienen la integración y el bienestar de la sociedad. Dewey, por ejemplo, propugnó que el conocimiento, por ser un instrumento que sirve a la consecución pragmática de fines y a la satisfacción de necesidades de ajuste, no tiene por finalidad la adquisición de la verdad. Para el utilitarismo no existen como principios autónomos ni la verdad ni la razón, sino una multiplicidad de ellas, tantas como sea preciso. El ataque de Rorty (1979), destacado representante del posmodernismo, al realismo, y su defensa del pragmatismo, siguieron un rumbo teórico parecido.

El constructivismo es una versión radical de la sociología del conocimiento de Durkheim y otros. De otros, como Marx y Engels, que plantaron las semillas de esta disciplina defendiendo que solo las circunstancias externas (económicas y políticas) participan en la génesis de las ideas. Los principios programáticos de Marx y Engels tuvieron su plasmación mucho más tarde en posiciones externalistas moderadas de explicación de la vida cultural, según las cuales todo conocimiento es socialmente condicionado $^{44}$. Sin embargo, media un amplio trecho entre el externalismo moderado y el radical. Aunque la sociología del conocimiento explica el individuo y la mayor parte de nuestro saber en términos sociológicos, aunque avanza hacia la disolución del individuo y la transferencia de su esencia a las relaciones sociales, no dio el paso que sí dio Fleck, autor del libro que inauguró el externalismo radical (víd. apartado 6).

radical, la negación del individuo humano y el culto de la humanidad como único individuum real -todo eso se encuentra formulado en sus textos» (Kolakowski 1988, p. 91).

42 Berger y Luckmann (1968), pp. 20-21.

43 Aunque estemos utilizando este término, propiamente, si nos adherimos a la distinción popperiana, deberíamos emplear el de «historismo» (Historismus) (cf. González Fernández 1984).

44 El exponente de externalismo moderado es el artículo de Hessen «The Social and Economic Roots of Newton's Principia» (1931). Este trabajo obtuvo un éxito inmediato y contribuyó a crear la sociología de la ciencia marxista occidental (que alcanzó su apogeo entre mediados de los años treinta y mediados de los sesenta del pasado siglo). 


\section{Negación de la naturaleza humana}

Crucial para entender la evolución hacia el constructivismo, la negación de la existencia de una naturaleza o esencia humana ha sido una tesis mantenida, con diversidad de formulaciones, por Marx (la idea sociologista de que la verdadera naturaleza del hombre es el conjunto de sus relaciones sociales), por el historicismo, por Heidegger y el existencialismo (Ortega, que escribió que el hombre no tiene naturaleza sino historia, se acercó a sus análisis), el estructuralismo, el posestructuralismo, etc. La negación de la naturaleza humana subyace a la conocida como doctrina de la tabula rasa de Locke. Fue un heredero intelectual de Locke, Mill, quien aplicó por vez primera esta doctrina al ámbito político, acusando de estar anclados en intereses conservadores a los intelectuales que sostenían que las diferencias entre los seres humanos y las categorías de la razón eran fundamentalmente innatas. Quizá asociada a la teoría del «buen salvaje» (Rousseau) y a la del «fantasma en la máquina» ${ }^{45}$ (Descartes $)^{46}$, la doctrina de la tabula rasa «ha fijado el orden del día de gran parte de las ciencias sociales y de las humanidades durante los últimos cien años $\rangle^{47}$; más en particular, «se atrincheró [...] en lo que se ha llamado el Modelo Estándar de Ciencia Social, o constructivismo social» ${ }^{48}$.

Un avance importante hacia la negación de la existencia de la naturaleza humana se debió a Kant. Como Ockham, Kant pensaba que la apreciación de cursos de acción que podemos decidir si seguir o no constituía un dato primario de la conciencia. Su filosofía moral es radicalmente voluntarista. Kant llamó autonomía a la primacía absoluta que concedió a la voluntad humana como principio indisponible del ser humano y de la moralidad. Para que un acto sea libre y por tanto moral, ha de estar absolutamente exento de determinaciones naturales, tanto exteriores (materiales, sociales) como interiores (pasiones, impulsos...). La diferencia entre el hombre y la naturaleza reside en que esta se rige de manera rigurosa por la ley de la causalidad y el hombre es libre de elegir lo que desea. «Kant estaba auténticamente intoxicado con la idea de la libertad humana $»^{49}$. El principio de que el hombre es hombre únicamente porque elige «se convirtió en un obsesivo principio central» ${ }^{50}$. Kant abre así un cisma profundo entre la voluntad y la libertad humanas, por una parte, y la naturaleza, en la que solo ve el ámbito del determinismo y de la sujeción del hombre, por la otra. En la doctrina kantiana, y este es el punto clave, la libertad acaba, en cierto modo, cancelando la naturaleza humana, porque, si no fuera así, el hombre estaría esclavizado, y la moralidad se convertiría en una mera ilusión. Estas proposiciones de Kant «ha[n] tenido consecuencias sumamente revolucionarias y subversivas que difícilmente él mismo pudo haber imaginado $»^{51}$.

Como muestra Pinker ${ }^{52}$, los inicios de la antropología y la sociología ahondaron en la idea de la negación de una naturaleza humana (confluyendo con la posición

45 La denominación de «fantasma en la máquina» fue acuñada por Ryle en El concepto de lo mental (1949) para designar a la teoría estrictamente dualista mente/cuerpo originada en Descartes.

46 Nos adherimos aquí a la tesis (de Pinker) que defiende esta asociación, pero creemos que precisa de investigaciones que la confirmen.

47 Pinker (2003), p. 26.

48 Ibid., pp. 40-41.

49 Berlin (2000), p. 100.

$50 \quad$ Ibid., p. 101.

51 Ibid., p. 111.

52 Pinker (2003), pp. 48-51. 
sociologista del pragmatismo, positivismo, etc.). En una interpretación extremada de las tesis de Boas, sus discípulos, que llegaron a dominar la ciencia social estadounidense, negaron la existencia de la naturaleza humana, el influjo de la herencia, y propugnaron la autonomía de la cultura respecto a las mentes individuales ${ }^{53}$, llegando alguno de ellos (Kroeber) a mantener que una cultura es «superorgánica», una especie de mente colectiva que flota en su propio ámbito, libre y por encima de los seres humanos. Uno de los fundadores de la sociología, Durkheim, explicitó también esas ideas ${ }^{54}$ y prefiguró la doctrina de la mente superorgánica; en este sentido, su teoría sociológica fue también una de las semillas del constructivismo (Durkheim fue quien acuñó la expresión «construcción social»). Las ciencias sociales iban a situar las creencias y los deseos en las culturas y las sociedades, no en la cabeza de los individuos, y todas iban a coincidir en el rechazo hacia los instintos y la evolución. «Destacados científicos sociales declaraban repetidamente que la tabla era rasa $\rangle^{55}$. «La mente superorgánica o de grupo se convirtió también en artículo de fe de la ciencia social $»^{56}$. En la naturaleza humana que se está negando, también está comprendida la racionalidad. Lévy-Bruhl, discípulo de Durkheim, había concluido que no hay una razón común a todas las culturas que esté por encima de sus diferentes costumbres y creencias. Quedaba así preparado el terreno para la instauración de un «paradigma» que no admite objetividad ni racionalidad en la ciencia y que reduce esta a creencias determinadas por el contexto en el que surgen.

\section{Fundación del constructivismo: el externalismo radical de Fleck y su continuación en Kuhn}

El médico y biólogo polaco Ludwik Fleck es considerado el autor del texto fundacional del constructivismo, La génesis y el desarrollo de un hecho cientifico $(1935)^{57}$, una obra que influyó en el joven Kuhn, como este reconoció. El libro de Fleck es adscribible al externalismo radical, a «la tesis de que todo conocimiento es social en contenido y función, además de en origen $\rangle^{58}$. El externalismo radical es una generalización y exageración de la tesis de Feuerbach-Durkheim de que todas las religiones son traducciones simbólicas y compresiones de estructuras sociales ${ }^{59}$.

El libro de Fleck es un estudio de la historia del pensamiento popular y médico sobre la sífilis, a la que el autor llamó «hecho científico», un producto generado por un «colectivo de pensamiento», o comunidad de individuos unidos por un «estilo de

53 Boas, padre de la antropología moderna, sostuvo la tesis de que la cultura configura la mente y que los individuos difieren porque difieren sus culturas. Boas defendía las explicaciones en términos sociales, y no hereditarios, de aspectos humanos complejos solo en tanto no se demostraran falsas. Boas no era un relativista que pensara que todas las culturas fueran equivalentes y no rechazaba la idea de que pudiera existir una naturaleza universal como un conjunto de disposiciones básicas.

54 Durkheim formuló una ley para las ciencias sociales que se hizo célebre: «La causa determinante de un hecho social debe buscarse entre los hechos sociales antecedentes, y no entre los estados de la conciencia individual» (Durkheim 1982, p. 133).

55 Pinker (2003), p. 51.

56 Ibid., p. 53.

57 En medio del consenso acerca de la atribución a Fleck del papel de fundador del constructivismo, una voz discordante es Fagan (2009).

58 Bunge (1998), p. 226.

59 Ibid. 
pensamiento». Para Fleck, la sífilis es una construcción mental, una construcción social llevada a cabo por la comunidad médica; como tal, no existe. En general, al sostener que los hechos son creaciones de este tipo, Fleck negaba que la ciencia estudiara hechos objetivos, cosas con existencia propia, y que un individuo pudiera pensar por sí mismo: «la realidad objetiva se puede descomponer en secuencias históricas de ideas pertenecientes al colectivo» ${ }^{60}$. El libro de Fleck sintetiza varias tradiciones ${ }^{61}$, que relacionamos por orden de importancia. La primera y determinante fue el idealismo alemán, con su identificación de realidad e idea. Una segunda es el sociologismo (comtiano, marxista, durkheimiano...), que se evidencia en la negación por parte de Fleck de que el individuo tenga algún papel en la generación de ideas y en su tesis de que todo hecho científico (en particular, todo descubrimiento o invención) constituye un hecho social. Estas dos corrientes Fleck las aglutina para formar su tan influyente socioidealismo, que atribuye la existencia del mundo a comunidades de pensadores. No obstante, fue la tradición idealista el factor que le propulsó a un punto donde la sociología y la antropología no llegaron. Fleck, después de mencionar admirativamente a Comte y de citar a Durkheim, Lévy-Bruhl, Gumplowicz y Jerusalem, les reprocha «un error característico: tienen un respeto demasiado grande, rayano en la veneración religiosa, por los hechos científicos [= objetivos] $\rangle^{62}$. La tercera influencia, procedente de la tradición historicista germana de las concepciones del mundo, es el relativismo cultural, ya que para Fleck la verdad y el error son conceptos sociales, no gnoseológicos: para él, el cambio en la ciencia se produce porque la sociedad cambia, no por eliminación de errores, abandono de ideas falsas y descubrimiento de otras verdaderas; la verdad es lo que el colectivo de pensamiento cree en un momento dado. Añadamos, al margen, una indicación acerca de la génesis del relativismo posmodernista y las influencias que lo han conformado. Berlin enumera, además de algunos de los autores y corrientes que se comentan en este trabajo (Schopenhauer, Nietzsche, las escuelas de antropología social, Marx), el irracionalismo romántico, Freud y las doctrinas de Graham Sumner y Westermarck ${ }^{63}$. Esta plétora induce a pensar que el problema histórico en este ámbito es particularmente espinoso, y de hecho se plantea ya desde el supuesto principio y origen del relativismo. Volviendo a Fleck, una cuarta influencia que recibe este autor se deriva de su reacción contra el Círculo de Viena y su espíritu formalista, que consideraba la lógica y la racionalidad «algo fijo y absoluto» ${ }^{64}$. Fleck le dio un giro al constructivismo de Carnap: el mundo lo construyen, no los individuos, sino las comunidades; más específicamente, las comunidades científicas ${ }^{65}$. En conclusión, la obra de Fleck es la primera -y una buena- muestra del «achatarramiento» y compactación que el constructivismo lleva a cabo de la tradición filosófica.

La estructura de las revoluciones cientificas (1962), de Kuhn, rescató del olvido a Fleck. De gran impacto en las décadas siguientes a su publicación ${ }^{66}$, la obra de Kuhn proponía la tesis de que la ciencia no es resultado de la acumulación

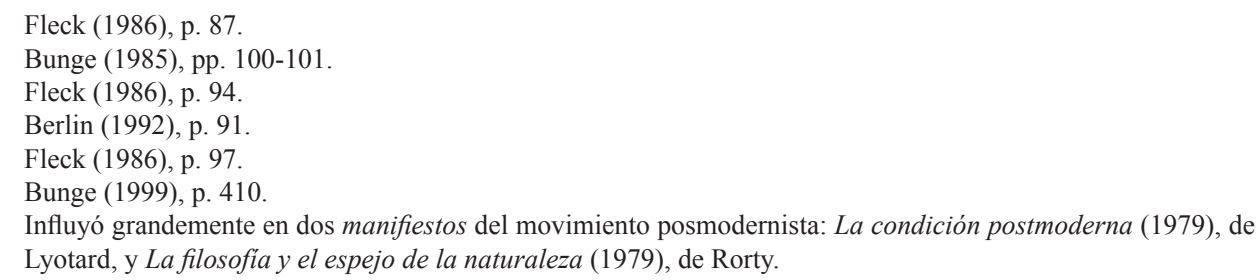


de conocimientos, sino que depende de la adquisición de un modelo o patrón de actuación, de «un paradigma capaz de guiar las investigaciones de todo el grupo» de científicos de un campo determinado ${ }^{67}$. Kuhn niega que existan métodos científicos universales; solo admite los relativos a un paradigma dado (entidad de carácter histórico y variable, producto de una discontinuidad con respecto al anterior), de modo que los conocimientos resultantes no son universalmente verdaderos ni falsos. Su idea de la «incomensurabilidad de paradigmas», de que enfoques y teorías rivales no son comparables entre sí, responde a la necesidad de articular teóricamente la opinión de que no existe un criterio de verdad único y universal. La postura relativista de Kuhn exagera las discontinuidades en la historia de la ciencia, y es, hasta cierto punto, también irracionalista porque defiende que el paradigma es fruto de prejuicios y otros elementos no racionales (intuición, metáfora). Además, es anticientífica, ya que pasa por alto la función de las matemáticas en la construcción de teorías y el papel de las pruebas empíricas adversas y de la crítica teórica, y no cree en la unidad de la ciencia ${ }^{68}$.

\section{Glosocentrismo, relativismo epistemológico}

Los antecedentes del glosocentrismo lo son del giro lingüístico en que se inscribe el constructivismo. La filosofía del lenguaje del período romántico (Hamann, Herder y Wilhelm von Humboldt) es el primero de esos antecedentes. Específicamente, el glosocentrismo parte de la problemática de que se ocuparon Frege y la filosofía analítica (Russell y el Wittgenstein del Tractatus logico-philosophicus), pero cobra su auténtica fisonomía con la influencia de Heidegger y del estructuralismo (Saussure) ${ }^{69}$, y con la hermenéutica filosófica (fundada por Dilthey). Esta última y el posestructuralismo son ya la estación término en este devenir de antecedentes e influencias, y sus representantes (Derrida, Foucault, Gadamer y Ricoeur, etc.) son los pioneros del giro lingüístico que se instaurará en las ciencias humanas y sociales (por ejemplo, en historia, con Hayden White).

Aquí soslayaremos la cuestión histórica de los antecedentes del giro lingüístico en general para centrarnos en la influencia directa que ha tenido la cuestión lingüística en la formación del constructivismo en particular. El segundo Wittgenstein, el Wittgenstein de las Investigaciones filosóficas (1953), de la teoría de los juegos del lenguaje, contribuyó a dar forma a la filosofía del constructivismo y a la actitud posmodernista respecto a la ciencia, confiriendo apariencia de solidez teórica a las tesis del movimiento. Pasando por alto el hecho de que el lenguaje articula y comunica el pensamiento, el segundo Wittgenstein lo considera un hecho pragmático, destinado a producir determinados efectos en aquellos a quienes se dirige. Semejante a una «caja de herramientas», el lenguaje ya no responde a la racionalidad general, sino que se organiza en múltiples juegos lingüísticos -cada uno de ellos dotado de sus propias reglas- que solo comparten entre sí un «aire de familia». Las palabras, en vez de sentido que las conecte con lo real, pasan a tener un alcance dependiente

\footnotetext{
Kuhn (1971), p. 50.

Bunge (1999), p. 437.

69 Hay una gran diferencia entre considerar, como hace la filosofía analítica, que el lenguaje interfiere en el conocimiento de la realidad, y mantener, como hace el giro lingüístico, que el lenguaje constituye la realidad.
} 
de los «usos del lenguaje» en cada momento. El significado de un término ha de buscarse en la función específica que cumple, en el uso que se hace de él en el lenguaje. La pragmática anula la semántica y la referencialidad. Se sugiere así que la discrecionalidad, no la veracidad, preside el acto comunicativo. El legado del segundo Wittgenstein fue recogido por la filosofía anglosajona del lenguaje ordinario (Ryle, Strawson, Grice, Austin, Searle...), prestigiada durante décadas, algunas de cuyas teorías (por ejemplo, el «significado como uso» de Strawson) contribuyeron a reforzar el relativismo cultural de los círculos posmodernistas. (La cancelación del nivel semántico y referencial también la operó el estructuralismo, una corriente que confluyó con las otras para desembocar en el posmodernismo. Omitiendo de entrada toda cuestión acerca del referente, el estructuralismo establece que las palabras carecen de significado aisladamente y que solo adquieren valor en virtud de sus relaciones dentro del sistema lingüístico).

En un eco de la aversión que mostraron Husserl y Heidegger a la ciencia y a la técnica, Lyotard redujo la realidad y la ciencia a juegos de lenguaje ${ }^{70}$, calcando al segundo Wittgenstein: los conjuntos de enunciados científicos "son "jugadas" realizadas por los jugadores en el marco de las reglas generales $\rangle^{71}$; los científicos son jugadores que aceptan las reglas del juego de la ciencia; incluso el mismo referente llega a ser tal solo en la medida en que se observan determinadas reglas... El corolario es que la teoría de los juegos del lenguaje abona la creencia relativista que equipara en validez el discurso científico con las fábulas, mitos y leyendas ${ }^{72}$. Abrazando la misma filosofía, Rorty defiende que la creencia en la existencia de montañas viene dada por la utilidad de jugar a determinados juegos de lenguaje que utilizan la palabra «montaña». «Dado que trae cuenta hablar de montañas, como sin duda sucede, una de las verdades obvias acerca de las montañas es que ya estaban allí antes de que empezáramos a hablar de ellas» ${ }^{73}$. Es este el sentido en que Rorty, y Kuhn y Derrida, aseveran que «carece de objeto preguntar si la realidad es independiente de nuestro modo de hablar de ella» ${ }^{74}$. Antes de describir algo de una manera dada, escribe Rorty, «no hay ningún sentido que pueda tener la afirmación de que está "ahí fuera" con sus propiedades» ${ }^{75}$. Y unas páginas más adelante, subraya que gentes como Goodman, Putnam y él mismo piensan que «no hay un modo de ser del mundo independiente de la descripción [que se haga de él], un modo en que el mundo sea sin que medie descripción de él $\rangle^{76}$. De ahí que, para ellos, la noción de verdad como correspondencia de los enunciados con la realidad carezca de sentido: «el proyecto de distinguir entre lo que existe en sí mismo y lo que existe en relación con las mentes humanas [...] ha dejado de merecer la pena [...]. Se ha revelado [históricamente] un callejón sin salida» ${ }^{77}$. En La filosofía y el espejo de la naturaleza, Rorty había declarado a Wittgenstein, Heidegger y Dewey los tres filósofos más importantes del siglo XX, porque los tres «están de acuerdo en que

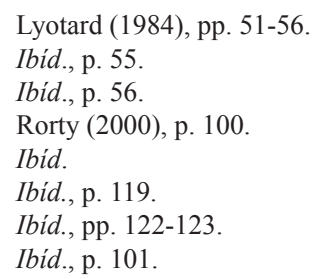


hay que abandonar la noción del conocimiento en cuanto representación exacta» ${ }^{78}$. Decidido a acabar con esa concepción y con la idea concomitante de la mente como espejo, Rorty ve el conocimiento «como una cuestión de conversación y de práctica social, más que como un intento de reflejar la naturaleza», como diálogo, y no como confrontación. La filosofía «no tiene nada que ver con la búsqueda de certeza» ${ }^{79}$.

\section{La tesis de la falsa conciencia}

El constructivismo, al aseverar que un hecho es socialmente construido, quiere «poner al descubierto un constructo allí donde no se sospechaba su existencia, es decir, donde algo constitutivamente social estaba siendo disfrazado como natural $\rangle^{80}$. Para Hacking, la idea de construcción social encierra en sí misma un potencial liberador, ya que predispone a que se dejen de ver como naturales, esto es, inmutables e inevitables, ciertas instituciones supuestamente opresoras, para considerarlas tan solo el producto de fuerzas sociales e históricas. Así, ya no cabría la actitud resignada ante lo inexorable de algunos hechos, porque, en tanto que fenómenos contingentes, son susceptibles de ser cambiados $^{81}$. Sin embargo, puntualiza Hacking, «[d] esgraciadamente, los análisis de construcción social no siempre liberan $\rangle^{82}$. Este autor advierte de la multiplicación desordenada y patológica de «hechos construidos»: «Una vez puesta la semilla, se reproducen sin control» ${ }^{83}$.

La pasión por extender los análisis en términos de construcción social mucho más allá de lo razonable se explica por la influencia de los filósofos de la sospecha: Nietzsche y Marx. Si creemos que ciertas cosas son verdad, no es por su evidencia, sino por una serie de motivos no epistémicos, como la ideología dominante o el egoísmo, a cuyo poder estaríamos sujetos. Ideología, según Marx y Engels, es el conjunto de representaciones (ideas, imágenes, símbolos, mitos...) y valores de la sociedad en un momento dado. La ideología dominante en cada momento enmascara los intereses materiales de la clase dominante y tiende a justificar la estructura económica del momento. De aquí se desprende que la ideología viene dada por la pertenencia de clase, y que es representación falsa, distorsionada (aunque inadvertida). Por su parte, Nietzsche introdujo la idea del pensamiento humano «como instrumento de lucha por la supervivencia y el poder». «Nietzsche desarrolló su propia teoría de la "falsa conciencia" con sus análisis del significado social del engaño y el autoengaño, y de la ilusión como condición necesaria para la vida», especifican Berger y Luckmann, reconociendo que las ideas de Nietzsche tuvieron mucho que ver con la atmósfera en la cual surgió la sociología del conocimiento y por ende con su propia teoría sociológica ${ }^{84}$.

Según Berger y Luckmann, la sociología del conocimiento es un saber que «representa una aplicación específica de lo que Nietzsche denominó con acierto el

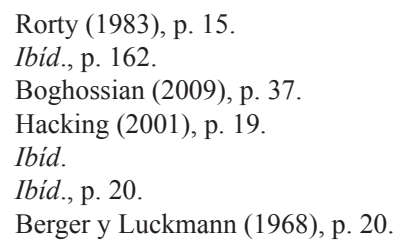


“arte de la desconfianza" $\gg{ }^{85}$. Así, la sociología del conocimiento contribuye, también en este sentido, a la formación del constructivismo. Reseñemos la figura de Mannheim, considerado el fundador de la disciplina. Inspirándose en Marx, Mannheim habló de un nuevo fenómeno en la historia de la razón, la «conciencia desenmascaradora», que no consiste tanto en tratar de refutar ideas, «como en disolverlas» desvelando «su funcionalidad extrateórica» (cursivas del autor), «de tal modo que a la vez se disuelva la imagen del mundo de un estrato social». Mannheim parte de la presunción de que, desenmascarada así una idea, esta queda despojada de un falso poder de atracción, exhortación o autoridad, perdiendo su efectividad práctica. El «desenmascaramiento sociológico de la ideología» desactiva su eficacia social ${ }^{86}$. Los constructivistas adoptan el reformismo desenmascarador de Mannheim: «creen no solo 1) que $X$ no es inevitable, sino también 2) que $X$ es algo malo, y probablemente 3) que nos iría mejor $\sin X \gg{ }^{87}$. El constructivismo es inseparable de los supuestos no epistémicos a que responde; es más, resulta justificado por ellos y los traduce en activismo político. Extiende los análisis en términos de construcción social a cualquier hecho que le interese por el potencial que contienen para la acción ${ }^{88}$. En conexión con esta idea, remarcamos aquí la influencia de lo que podría denominarse «marxismo cultural» (Gramsci, Lukács, Teoría Crítica de la Escuela de Fráncfort, deconstrucción...), según el cual todas las dimensiones de hegemonía cultural son producto de una opresión de clase, sexual, religiosa, etc. que hay que derribar.

El problema que se plantea es claro. Los constructivistas incurren en la paradoja de tratar de desmontar los constructos basándose en unas motivaciones y supuestos ideológicos análogos a los que, según ellos, inspiraron la elaboración de dichos constructos. La posición constructivista entraña el inevitable conflicto con la rival, además de su autoinvalidación. Si corrientes antagónicas o distintas mantienen el mismo punto de vista acerca del papel de los conceptos y teorías, acaban por acusarse recíprocamente de ideología. Así, se desarrollan en una misma sociedad universos mentales independientes y mutuamente excluyentes que coexisten vinculados por «una desconfianza activa y recíproca entre los grupos» ${ }^{89}$. Un proceso que, según Merton, se incrementa «en una sociedad en que grandes grupos de individuos ya se han extrañado de los valores comunes $\rangle^{90}$. Por otro lado, llevado a sus últimas consecuencias, el concepto marxista de ideología acarrea absurdos lógicos y nihilismo intelectual. Siendo consciente de ello, Mannheim trató de salir del callejón sin salida relativista, pero en vano ${ }^{91}$. Con todo, el concepto ha conocido una fortuna considerable, hasta el punto de impregnar el pensamiento de influyentes movimientos como el ya señalado «marxismo cultural». La filosofía de la sospecha de Marx ha logrado que no nos preguntemos ya si una determinada tesis es verdadera o falsa, o si un determinado razonamiento o ley están válidamente deducidos, sino que, en

\footnotetext{
Ibid.

Mannheim (1990), pp. 10-14.

Hacking (2001), p. 47.

88 Por supuesto, esta actitud goza en la actualidad de plena vigencia. La sostienen, entre otros, Díaz-León (2015) y Marques (2017).

89 Merton (1980), p. 542 (cursiva del autor).

90 Ibíd., p. 543. Sartori, siguiendo a Merton, advierte de las consecuencias de esta dinámica: «una cacería de brujas, en la que cazador y cazados son, todos, igualmente brujas. Si la mía es ideología, también la de quien me contradice es ideología. [...] Falsa conciencia la mía, falsa conciencia la suya. De este modo, no solo invertimos tiempo y energía en vano, sino que quedamos cada vez más atrás en el saber» (Sartori 2003, p. 352).

91 El análisis de los intentos frustrados de Mannheim se puede encontrar en Merton (1980), pp. 588-594.
} 
vez de ello, inquiramos a quién le benefician y qué intereses se ocultan detrás. «Se funcionaliza el pensamiento -señala Merton-, se le interpreta en relación con sus fuentes y sus funciones psicológicas, económicas, sociales o raciales» ${ }^{92}$.

La tesis del «marxismo cultural» que afirma que el conocimiento no representa el mundo, sino que es un instrumento de poder, conduce a sospechar de todo «discurso», también del científico-matemático. Este «escepticismo patológico» y «gnoseología paranoide», como se ha llamado a esta actitud, se vinculó con el relativismo epistemológico. Según el relativismo epistemológico -que es la semilla del anarquismo gnoseológico de Feyerabend (Contra el método, 1975)-, no habría diferencia entre una mente moderna crítica y una mente primitiva, entre una visión mítico-mágica y la ciencia, entre el conocimiento científico y la pseudociencia. Si todos los hechos son creaciones de uno u otro grupo social, no puede haber verdades objetivas sobre ellos, ni pruebas de verdad o estándares de objetividad universales. La validez de cualquier proposición o razonamiento entonces es relativa a cada grupo, cultura o circunstancia; hay tantas verdades como colectivos, hay pluralidad de creencias, y de ninguna puede declararse que es superior a las otras. Fue quizá Nietzsche quien expuso por vez primera la doble tesis de la sospecha y el relativismo epistemológicos; más tarde la recogieron, además del «marxismo cultural», Foucault, Rorty, Ross, Aronowitz, y el posmodernismo en general.

Cabe resaltar en este contexto la peculiar tendencia que muestra el constructivismo a fagocitar teorías para su propio beneficio. La tesis de Duhem-Quine de la subdeterminación, «una nueva versión del escepticismo radical humeano ${ }^{93}$, sostiene que un conjunto cualquiera de datos empíricos se puede explicar mediante dos o más teorías. Duhem la utilizó para atacar al realismo científico argumentando que las controversias en ciencia se dirimen recurriendo a criterios no científicos como la simplicidad. Pero mientras los criterios extracientíficos a que se refieren posturas convencionalistas como la de Duhem son de todos modos criterios conceptuales, los constructivistas se apropian de la tesis de la subdeterminación para sustentar su afirmación de que todas las controversias científicas pueden resolverse por medios no cognoscitivos como la política ${ }^{94}$. Esta apropiación suministra cobertura teórica a una visión relativista que nada quiere saber de verdad cognoscitiva y a la tesis de que todas las construcciones, incluso las científicas, esconden siempre una finalidad política.

El constructivismo se ha venido identificando a veces con su representante más conspicuo: el ya citado «Programa Fuerte» de la Sociología del Conocimiento Científico de la Universidad de Edimburgo, surgido bajo el efecto de Kuhn y Feyerabend, la filosofía lingüística de Wittgenstein, la hermenéutica filosófica, el existencialismo, la fenomenología, etc. (actualmente, habiendo perdido relevancia dicho «Programa Fuerte» y sus corrientes asociadas, el relevo del constructivismo lo han tomado otras teorías y la obra de antropólogos e historiadores culturales y de epistemólogas feministas de la ciencia ${ }^{95}$. Según la crítica de Bunge, la sociología del conocimiento posmertoniana es anticientífica porque niega que la investigación científica básica sea una actividad especial, racional, objetiva, desinteresada y benigna

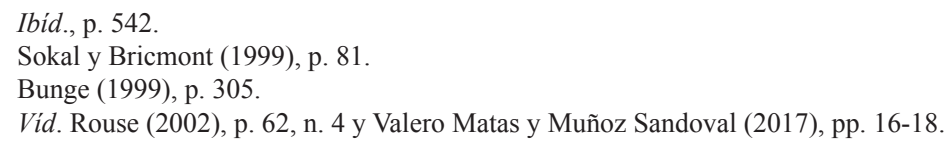


(en particular, piensa que los científicos no colaboran entre sí para comprender la realidad, sino que luchan por el poder ${ }^{96}$. De manera general, como vemos, el concepto de poder ha sido utilizado como caballo de batalla dialéctico por quienes se han afanado en cargar contra la ciencia. «En todas las pseudociencias encontramos un denominador común: el miedo social a la ciencia y la técnica difundido por intelectuales ${ }^{97}$.

\section{Conclusión}

El enfoque histórico que hemos empleado en este artículo, en su estado germinal actual, está erizado de problemas metodológicos. «Es muy difícil, si no imposible, describir correctamente la historia de un campo del saber. Esta se compone de muchas líneas de desarrollo de ideas, que se cruzan y se influyen mutuamente ${ }^{98}$. No deja de ser significativo que el autor de estas palabras fuera el «fundador» de una de las principales «líneas» que dieron lugar al posmodernismo, a su vez deudora de otras líneas. Todas las líneas, prosigue Fleck, «tendrían que ser representadas, primero, como líneas continuas y después, en un segundo momento, con todas las conexiones establecidas entre ellas. En tercer lugar, se tendría que trazar, simultáneamente y aparte, la dirección principal del desarrollo, tomada como una media idealizada ${ }^{99}$. Fleck continúa desgranando otras complejidades del enfoque. Valgan las mencionadas para indicar que este artículo no trata de ser más que un empeño que adopta esta orientación. Curiosamente, la aplica a su área de estudio el aludido autor, criticado aquí. Pero las semejanzas del presente trabajo con el suyo terminan en este punto, es decir, en la intuición, certera, de cuáles son algunas de las tareas que debe asumir el nuevo historiador de las ideas. La perspectiva de Fleck es idealista, sociologista, relativista e irracionalista, y huelga decir que una historia de las ideas no puede basarse en esos supuestos. La investigación en el área de la historia de las ideas debe tender a seguir los principios del enfoque científico. Además, en tanto que aspira a ser más que un registro, opera con una perspectiva evaluativa (no teleológica) sobre su objeto de estudio semejante a la que ya es usual en otras disciplinas históricas (historia del arte, historia de la ciencia...). Una actitud evaluativa que es dictada por la adhesión al valor supremo que guía al conocimiento genuino: la verdad. En definitiva, y por expresarlo sucintamente, la historia de las ideas no puede ni debe ser posmodernista.

\section{Referencias bibliográficas}

Berger, P. L. y T. Luckmann (1968): La construcción social de la realidad, Buenos Aires, Amorrortu.

Berlin, I. (2000): Las raices del romanticismo, ed. de Henry Hardy, Madrid, Taurus.

Berlin, I. (1983): «Hume y las fuentes del antirracionalismo alemán», en Contra la corriente:

\footnotetext{
$96 \quad$ Bunge (1998), p. 234.

97 Valero Matas y Muñoz Sandoval (2017), p. 10.

98 Fleck (1986), p. 61.

99 Ibid.
} 
ensayos sobre historia de las ideas, ed. de Henry Hardy, México, Fondo de Cultura Económica, pp. 233-260.

Berlin, I. (1992): «El supuesto relativismo del pensamiento europeo del siglo XVIII», en El fuste torcido de la humanidad, ed. de Henry Hardy, Barcelona, Península, pp. 85-101.

Boghossian, P. (2009): El miedo al conocimiento: contra el relativismo y el constructivismo, Madrid, Alianza.

Bunge, M. (1983): Treatise on Basic Philosophy, vol. VI, Understanding the World, Dordrecht, D. Reidel.

Bunge, M. (1985): Seudociencia e ideología, Madrid, Alianza.

Bunge, M. (1999): Buscar la filosofía en las ciencias sociales, México, Siglo Veintiuno.

Bunge, M. (1998): Social Science under Debate: A Philosophical Perspective, Toronto, University of Toronto Press.

Bunge, M. (2002): Crisis y reconstrucción de la filosofía, Barcelona, Gedisa.

Bunge, M. (2006): Chasing Reality: Strife Over Realism, Toronto, University of Toronto Press.

Copleston, F. (1979): Historia de la filosofía: vol. III, De Ockham a Suárez, Barcelona, Ariel.

Delumeau, J. (1992): La confesión y el perdón: las dificultades de la confesión, siglos XIII a XVIII, Madrid, Alianza.

DeVries, W. (2016): «Wilfrid Sellars», en E. N. Zalta (ed.), The Stanford Encyclopedia of Philosophy, URL $=<$ https://plato.stanford.edu/archives/win2016/entries/sellars/>.

Díaz-León, E. (2015): «What is social construction?», European Journal of Philosophy 23(4), pp. 1137-1152, <doi: 10.1111/ejop.12033>.

Durkheim, É. (1982): Las reglas del método sociológico, Barcelona, Orbis.

Fagan, M. B. (2009): «Fleck and the social constitution of scientific objectivity», Studies in History and Philosophy of Science Part C: Studies in History and Philosophy of Biological and Biomedical Sciences 40(4), pp. 272-285, <doi: 10.1016/j.shpsc.2009.09.005>.

Finkielkraut, A. (1988): La derrota del pensamiento, Barcelona, Anagrama.

Fleck, L. (1986): La génesis y el desarrollo de un hecho cientifico: introducción a la teoría del estilo de pensamiento y del colectivo de pensamiento, Madrid, Alianza.

González Fernández, W. J. (1984): «La interpretación historicista de las ciencias sociales», Anales de Filosofía 2, pp. 109-137.

Hacking, I. (2001): ¿La construcción social de qué?, Barcelona, Paidós.

Husserl, E. (1997): Meditaciones cartesianas, Madrid, Tecnos.

Kolakowski, L. (1988): La filosofía positivista: ciencia y filosofía, Madrid, Cátedra.

Kuhn, T. S. (1971): La estructura de las revoluciones cientificas, México, Fondo de Cultura Económica.

Kukla, A. (2000): Social constructivism and the philosophy of science, London, Routledge.

Latour, B. y S. Woolgar (1995): La vida en el laboratorio: la construcción de los hechos cientificos, Madrid, Alianza.

Lyotard, J.-F. (1984): La condición postmoderna: informe sobre el saber, Madrid, Cátedra.

Mallon, R. (2019): «Naturalistic approaches to social construction», en E. N. Zalta (ed.), The Stanford Encyclopedia of Philosophy (Spring 2019 Edition), URL = https://plato. stanford.edu/archives/spr2019/entries/social-construction-naturalistic.

Mannheim, K. (1990): El problema de una sociología del saber, Madrid, Tecnos.

Marques, T. (2017): «The relevance of causal social construction», Journal of Social Ontology 3(1), pp. 1-25, <doi: 10.1515/jso-2016-0018>.

McKinley, J. (2015): «Critical argument and writer identity: social constructivism as a theoretical framework for EFL academic writing», Critical Inquiry in Language Studies 
12(3), pp. 184-207, <doi: 10.1080/15427587.2015.1060558>.

Merton, R. K. (1980): Teoría y estructura sociales, México, Fondo de Cultura Económica.

Miller, H. T. (2016): «From social constructivist epistemology to context realism», Critical Policy Studies 10(3), pp. 365-379, <doi: 10.1080/19460171.2016.1200476>.

Pinker, S. (2003): La tabla rasa: la negación moderna de la naturaleza humana, Barcelona, Paidós.

Rorty, R. (ed.) (1967): The Linguistic Turn: Recent Essays in Philosophical Method, ChicagoLondon, The University of Chicago Press.

Rorty, R. (1983): La filosofía y el espejo de la naturaleza, Madrid, Cátedra.

Rorty, R. (2000): Verdad y progreso. Escritos filosóficos, 3, Barcelona, Paidós.

Rouse, J. (2002): «Vampires: Social constructivism, realism, and other philosophical undead», History and Theory 41, pp. 60-78, <doi: 10.1111/1468-2303.00191>.

Sartori, G. (2003): ¿Qué es la democracia?, Madrid, Taurus.

Sokal, A. y J. Bricmont (1999): Imposturas intelectuales, Barcelona, Paidós.

Taylor, S. P. (2018): «Critical realism vs social constructionism \& social constructivism: application to a social housing research study», International Journal of Sciences: Basic and Applied Research 37(2), pp. 216-222.

Valero Matas, J. A. (2004): «Sociología de la ciencia: Un análisis posmertoniano», en J. A. Valero Matas (coord.), Sociología de la ciencia, Madrid, Edaf, pp. 81-140.

Valero Matas, J. A. y C. A. Muñoz Sandoval (2017): «Las pseudociencias como problema social en la era tecnocientífica. Un recorrido por la ciencia y sus enemigos dentro y fuera», Aposta. Revista de Ciencias Sociales 75, pp. 8-34.

Wittgenstein, L. (1988): Investigaciones filosóficas, Barcelona, Crítica. 